pp 1654-1665. (C) The Author(s), 2021. Published by Cambridge University Press on behalf of Royal Aeronautical Society. This is an Open Access article, distributed under the terms of the Creative Commons Attribution licence (http://creativecommons.org/licenses/by/4.0/), which permits unrestricted re-use, distribution, and reproduction in any medium, provided the original work is properly cited.

doi:10.1017/aer.2021.36

\title{
Propulsion system integration for a first-generation hydrogen civil airliner?
}

\author{
J. Huete ${ }^{(D)}$, D. Nalianda and P. Pilidis \\ jon.huete@cranfield.ac.uk \\ Thermal Power \& Propulsion Engineering \\ Cranfield University \\ Beds MK430AL \\ UK
}

\section{ABSTRACT}

An unusual philosophical approach is proposed here to decarbonise larger civil aircraft that fly long ranges and consume a large fraction of civil aviation fuel. These inject an important amount of carbon emissions into the atmosphere, and holistic decarbonising solutions must consider this sector. A philosophical-analytical investigation is reported here on the feasibility of an airliner family to fly over long ranges and assist in the elimination of carbon dioxide emissions from civil aviation.

Backed by state-of-the-art correlations and engine performance integration analytical tools, a family of large airliners is proposed based on the development and integration of the body of a very large two-deck four-engine airliner with the engines, wings and flight control surfaces of a very long-range twin widebody jet. The proposal is for a derivative design and not a retrofit. This derivative design may enable a swifter entry to service.

The main contribution of this study is a philosophical one: a carefully evaluated aircraft family that appears to have very good potential for first-generation hydrogen-fuelled airliners using gas turbine engines for propulsion. This family offers three variants: a 380-passenger aircraft with a range of 3,300nm, a 330-passenger aircraft with a range of 4,800nm and a 230passenger aircraft with a range of $5,500 \mathrm{~nm}$. The latter range is crucially important because it permits travel from anywhere in the globe to anywhere else with only one stop. The jet engine of choice is a $450 \mathrm{kN}$ high-bypass turbofan.

Keywords: Decarbonisation; Hydrogen; Long Range 


\section{NOMENCLATURE}

$\begin{array}{ll}\Delta & \text { change } \\ \text { BPR } & \text { bypass ratio } \\ \text { ESFC } & \text { energy SFC (W/N) } \\ \text { FCV } & \text { fuel calorific value (lower) }(\mathrm{MJ} / \mathrm{kg}) \\ \text { Fn } & \text { net thrust }(\mathrm{kN}) \\ \text { HVLER } & \text { aircraft variant }- \text { hydrogen very large aircraft extended range } \\ \text { HVLLR } & \text { aircraft variant }- \text { hydrogen very large aircraft long range } \\ \text { HVLMR } & \text { aircraft variant }- \text { hydrogen very large aircraft medium range } \\ \text { ISA } & \text { international standard atmosphere } \\ \text { NOx } & \text { nitrogen oxides } \\ \text { SFC } & \text { specific fuel consumption }(\mathrm{kg} / \mathrm{s} / \mathrm{MN}) \\ \text { SLS } & \text { sea level static } \\ \text { TET } & \text { turbine entry temperature }(\mathrm{K})\end{array}$

\subsection{INTRODUCTION AND ANALYSIS METHOD}

The use of hydrogen as a civil aviation fuel is an alternative to decarbonise aviation ${ }^{(1-3)}$. Switching jet engine fuel to hydrogen promises to decarbonise civil aviation if hydrogen production is carbon free and aircraft engines deliver very low NOx emissions. Hydrogen also removes other harmful emissions such as unburnt hydrocarbons, aromatic compounds, sulphur oxides, soot and smoke. However, the use of hydrogen for civil aviation requires colossal changes in aircraft, infrastructure, management, safety and regulation. Such a change will be very expensive. However, the authors firmly believe that, socially and economically, it is a far superior alternative to the vast economic and social damage that will result from reducing air traffic. Hydrogen is a technological solution to provide combined sustainability in environmental, economic and social terms. With the appropriate (very large) investments, an introduction in approximately 15 years is conceivable.

Many tests and evaluations of hydrogen-fuelled aircraft have been carried out, from von Ohain's hydrogen-fuelled demonstrator in the late $1930 \mathrm{~s}^{(4)}$, the flight test of a B57-Canberra in the late $1950 \mathrm{~s}^{(5)}$ and the TU-155 in the late $1980 \mathrm{~s}^{(6)}$. More recently, significant tests at engine conditions to deliver hydrogen combustion with low NOx emissions are being carried out in the European project Enable $\mathrm{H} 2^{(1)}$.

For a swift change, several waves of innovation are needed. For early service (2035?), the first wave must maximise the use of existing design and technology. Later waves of innovation will deliver the full potential of hydrogen in the aircraft.

This study examines a possible scenario into the first innovation wave to offer aircraft decarbonisation scenarios long before 2050 by maximising the use of the current state of the art. This approach will enable a reduction of development costs and concentrate scarce research resources in the key hydrogen focused components. Such initial aircraft designs will not be optimal, but they may reduce development time and risk. It is hoped that this could bring entry into service forward by 15 years or more. The carbon savings achieved would be colossal. The authors ask: why not fully decarbonise civil aviation in 50 years? Figure 1 


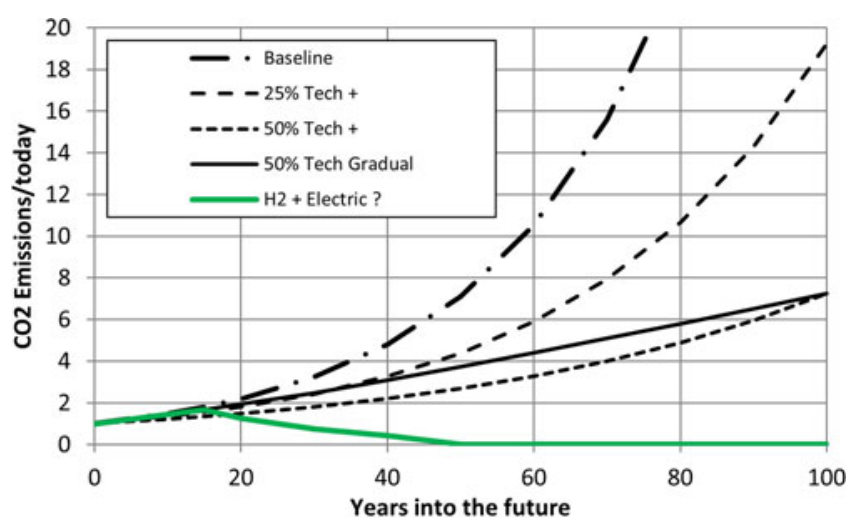

Figure 1. Comparison of five technology scenarios, all with the hypothesis of continuous growth in air traffic of $4 \%$ p/a. Baseline shows $\mathrm{CO}_{2}$ emissions with the continued use of current state-of-the-art equipment. The $25 \%$ and $50 \%$ results show the benefits of the immediate introduction of improved technology improvements that would yield, in 100 years, these respective improvements. The $50 \%$ gradual results show a gradual move to $50 \%$, and $\mathrm{H} 2+$ Electric shows a fully decarbonised scenario.

shows a scenario where five technology options are compared. The authors believe that the zero-carbon option in 50 years is feasible if decisive and wide-ranging international action is taken.

It is widely acknowledged that market forces alone will not bring about the changes needed. It would be necessary to adopt direct international financial support or economic-taxation measures to enable the transition to zero-carbon aviation. Techniques for evaluating the impact of different policy scenarios are available ${ }^{(7)}$.

Fast decarbonisation is possible if successive waves of innovation are considered. In the first wave, for fast implementation, Fig. $2 b$ shows how such a first wave of innovation could be shared between electric (including all electric, fuel cell electric and hybrid) and hydrogen propulsion systems. This may give rise to an increase in popularity of hub-and-spoke systems (Fig. 3) where inter-hub traffic is served by hydrogen-fuelled transports with gas turbine engines and the spokes by all-electric, fuel-cell electric and hybrid electric aircraft.

The maximum estimated range of the 'Hydrogen for GTs' bubble in Fig. 2b is shown at $5,500 \mathrm{~nm}$ based on the results for the HVLER aircraft variant analysed here. In the longer term, third- and fourth-generation aircraft could be designed to exploit the synergies between electrical and hydrogen systems ${ }^{(9)}$ to deliver improved engine and aircraft performance.

The study described here follows such an approach for a propulsion system in a medium/long-range aircraft design, where the focus is on the first wave of innovation aimed at a swift entry into service and the environmental reward is achieved by the faster deployment of carbon-free systems replacing carbon-emitting equipment. An attempt is made, via a hypothetical but reasonable approach, to answer a key question: What would a hydrogenfuelled propulsion system look like if integrated into existing airliner design experience? A realistic option is proposed based on a derivative design inspired by existing technology for a wide-body transport.

Through evaluation and analysis, the option of using an existing aircraft to achieve this objective was ruled out; it was apparent that such a vehicle would be very inefficient. A careful evaluation procedure was introduced (Huete et al. 2020-1) to down-select a reasonable vehicle from a wide range of options. It was concluded that the volume-mass relationships are such 


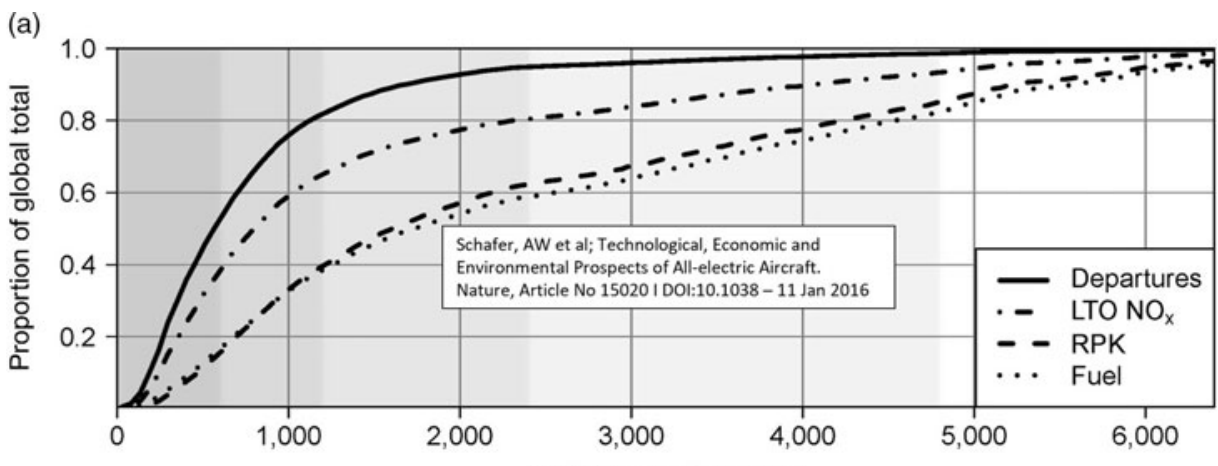

Distance, nautical miles

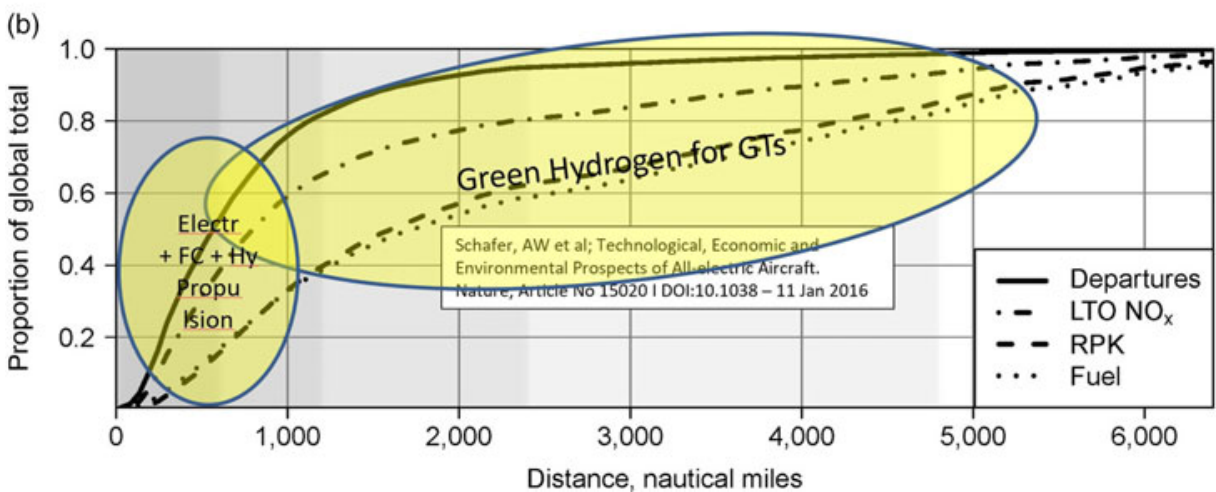

Figure 2 (a). Commercial aircraft traffic characteristics ${ }^{(8)}$. (b) Commercial aircraft traffic characteristics ${ }^{(8)}$ annotated by the authors on the basis of published electric propulsion capabilities and the $\mathrm{H}_{2}$ evaluation described here.

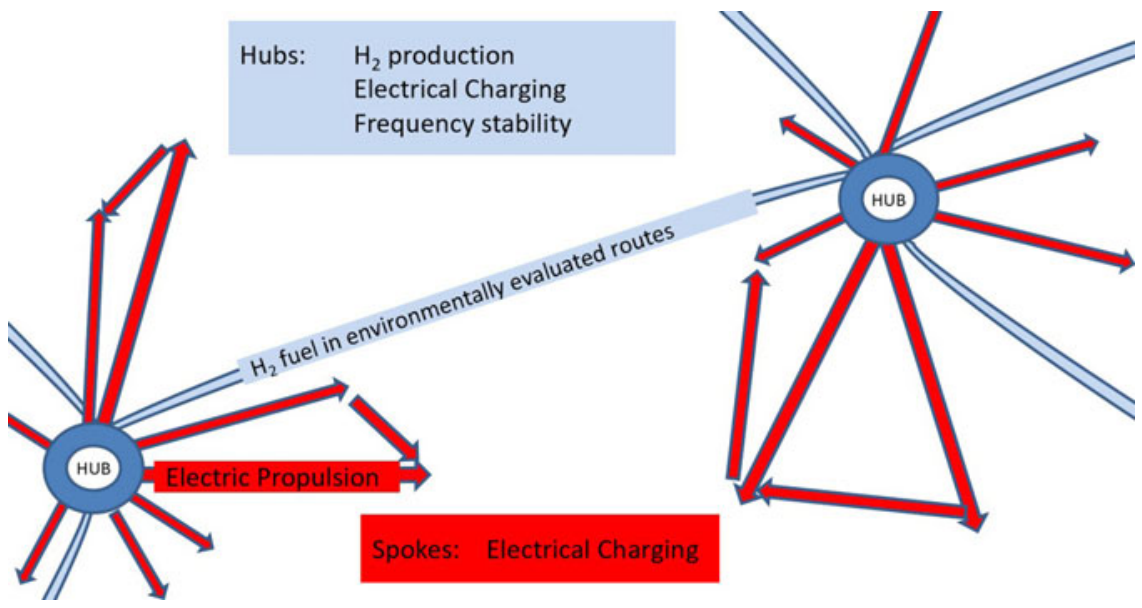

Figure 3. Schematic of hydrogen hub and electric propulsion spoke approach. 


\section{Table 1 \\ Cycle characteristics of the turbofan engine}

\begin{tabular}{|c|c|c|c|c|c|c|}
\hline & $\begin{array}{l}\text { Conv } \\
\text { Fuel }\end{array}$ & $\begin{array}{c}\text { H2 } \\
\text { Same } \\
\text { TET }\end{array}$ & $\begin{array}{c}\text { H2 } \\
\text { Same } \\
\text { Fn }\end{array}$ & $\begin{array}{l}\text { Conv } \\
\text { Fuel }\end{array}$ & $\begin{array}{c}\text { H2 } \\
\text { Same } \\
\text { TET }\end{array}$ & $\begin{array}{c}\text { H2 } \\
\text { Same } \\
\text { Fn }\end{array}$ \\
\hline & \multicolumn{3}{|c|}{ Take-off } & \multicolumn{3}{|c|}{ Cruise } \\
\hline Mass flow (kg/s) & $1,449.6$ & $1,449.6$ & $1,427.0$ & 597.2 & 612.9 & 587.3 \\
\hline Fuel flow (kg/s) & 3.8159 & 1.488 & 1.4093 & 1.4400 & 0.6037 & 0.4999 \\
\hline Turbine entry temperature $(\mathrm{K})$ & 1,865 & 1,865 & 1,837 & 1,760 & 1,760 & 1,660 \\
\hline Net thrust $(\mathrm{kN})$ & 448.1 & 463.9 & 447.9 & 89.1 & 103.8 & 89.2 \\
\hline Exhaust gas temperature $(\mathrm{K})$ & 957 & 1016 & 998 & 893 & 947 & 885 \\
\hline Exhaust mass flow $(\mathrm{kg} / \mathrm{s})$ & 155.6 & 153.3 & 148.8 & 61.1 & 65.9 & 59.9 \\
\hline Compressor discharge pressure $(\mathrm{kPa})$ & 4,941 & 4,941 & 4,764 & 1,882 & 2,067 & 1,830 \\
\hline Compressor discharge temperature (K) & 943 & 919 & 908 & 856 & 846 & 809 \\
\hline Compressor mass flow $(\mathrm{kg} / \mathrm{s})$ & 149.5 & 149.5 & 145.1 & 58.8 & 64.4 & 58.5 \\
\hline Compressor pressure ratio & 48.76 & 48.76 & 47.02 & 51.77 & 56.87 & 50.35 \\
\hline
\end{tabular}

that a reasonable approach would be to consider a design that integrated the airframe of a 600tonne double-decker airliner (inspired by the Airbus A380 ${ }^{(10)}$ ), with the wing and engines of a long-range twin-engine airliner (inspired by the Airbus A350-1000 with its Trent XWB turbofans $\left.{ }^{(11)}\right)$. The evaluation was an iterative process, and only the final result is shown here. This exercise gave rise to a family of three aircraft variants, labelled HVLMR, HVLLR and HVLER.

It is clear that integrating the necessary components would not be a straightforward matter, and the approach proposed here is a derivative design and not a retrofit. This could be accomplished within 15 years if sufficient research budgets are allocated very soon. It is also acknowledged that a significant challenge will arise from the systems needed to store, move and use hydrogen on board, the development of certification requirements, delivery of low NOx emissions systems and public support to decarbonise the sector. This public support is likely to be of a similar magnitude to the public investments and subsidies that underpinned the widespread use of renewable energy systems in the electricity generation industry.

\subsection{ENGINE CHARACTERISTICS}

The evaluation was an iterative process, concluding with the selection of a baseline jet engine that is inspired by a state-of-the-art high-bypass-ratio three-spool turbofan (Trent XWB ${ }^{(12)}$ ). Uisng TURBOMATCH (the Cranfield gas turbine performance simulation code ${ }^{(13)}$ ) the performance of turbofans using conventional and hydrogen fuels was evaluated. The TURBOMATCH analytical method uses gas turbine performance principles ${ }^{(14)}$ and is an iterative method based on component characteristics.

As expected, there are no major differences in engine performance arising from the use of hydrogen fuel, as shown in Table 1. SFC is expressed in a conventional way and also as ESFC, philosophically akin to the concept of heat rate, in wide use for land-based gas turbines. This is necessary because of the very large difference in the lower fuel calorific values, FCV, of conventional fuel and hydrogen $(43.1 \text { and } 120 \mathrm{MJ} / \mathrm{kg} \text {, respectively })^{(15)}$. The engine used in the 

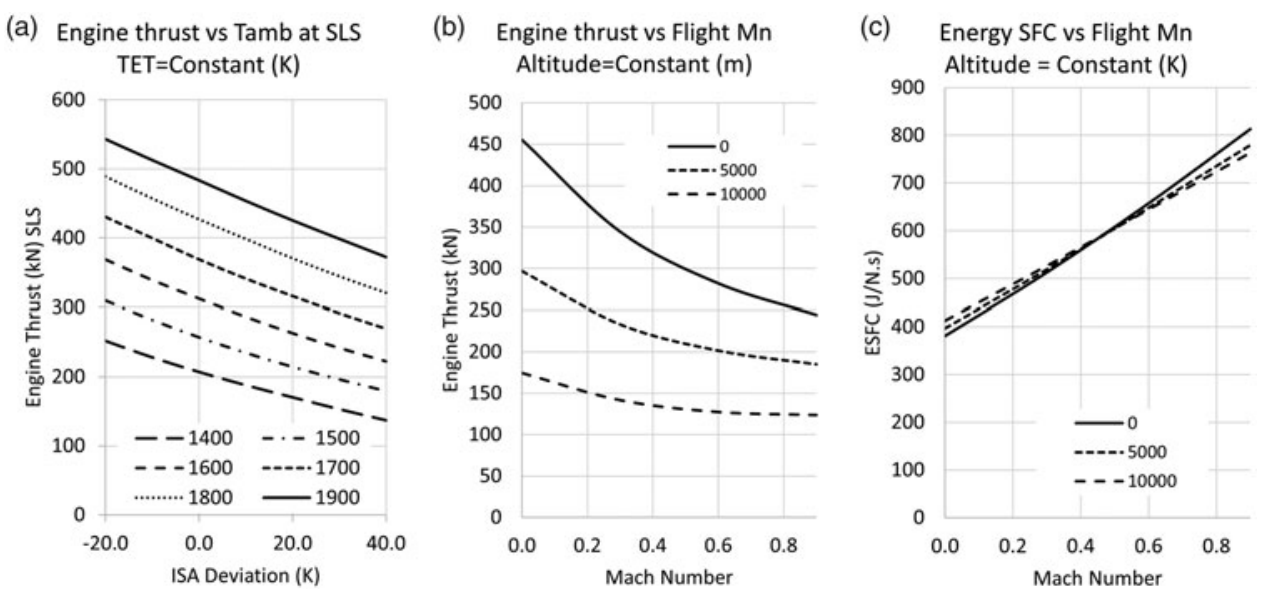

Figure 4 (a). Thrust versus SLS ISA temperature deviation. (b) Thrust versus flight Mach number. (c) ESFC versus flight Mach number.

three aircraft variants described below is always the same. The engine is designed for the aircraft variant with the highest thrust requirement; the lower thrust requirement of the other variants is met by adjusting the engine power setting.

The next step was an assessment of engine performance throughout the flight envelope using TURBOMATCH with hydrogen fuel in the calculations. The outputs are shown in Fig. 4, showing the thrust variation with ambient temperature (Fig. 4a) and with altitude and flight Mach number (Fig. 4b). Figure 4c shows the ESFC and its dependence on altitude and flight Mach number.

\subsection{FUEL TANK INTEGRATION}

A major challenge with the use of hydrogen is the low density of the fuel, even in its liquid form. The fuel is to be stored at $21.5 \mathrm{~K}$ and $1.25 \mathrm{bar}$, so insulation will require a great deal of attention. The authors based the tank design philosophy on expanded analytical studies based on previous Cranfield work ${ }^{(16-18)}$. The tanks must be insulated to prevent heat leakage into the liquid hydrogen with no need for an active cooling system. Low-pressure storage does not demand thick walls. Fuel withdrawals through engine feeding lines reduce the tank pressure and temperature, while heat leakage increases them. Pressure and temperature is regulated through two mechanisms. To prevent excessive increases in pressure and temperature, due to heat leakage, a bleeding valve allows hydrogen to escape to a venting space in a safe way, restoring the pressure and temperature inside the tank. To avoid undesirably low pressure inside the tanks, warmer or preheated hydrogen can be fed back into the tanks from feeding or venting lines.

Several design schemes are possible, with either single or double metallic or composite walls. A wide range of insulation materials from foam to vacuum-jacketed multilayer insulation can be used. The resulting tanks deliver insulation properties ranging from nearly zero boil-off over extended periods of time, typically days, to short-range tanks, that can accomplish a 6 mission with boil-off rates below $0.15 \%$ per hour $^{(16)}$ (p. 3). Tank selection depends on not only the mission but also the infrastructure developed at airports for hydrogen aircraft. For airports without hydrogen infrastructure, requiring aircraft to arrive and park with 


\title{
Table 2
}

\section{Comparison HVLMR, HVLLR and HVLER with the 'design donor' aircraft}

\author{
AIRBUS AIRBUS \\ A350-1000 A380-800 HVLMR HVLLR HVLER
}

Mass (tonnes)
Ramp
Max. take-off
Max. landing
Max. payload
Operational empty
$\mathrm{H}_{2}$ tank (gravimetric eff. 0.45$)$
Engines
Cruise thrust/engine $(\mathrm{kN})$
Static thrust/engine $(\mathrm{kN})$
Range (nm)
Pax

317
316
236
68
155

2
87
432
8,700
315

577
575
394
83
276

4
81
374
8,000
555

$$
\begin{array}{r}
274 \\
273 \\
251 \\
500 \\
200 \\
33 \\
2 \\
81 \\
406 \\
3,300 \\
388
\end{array}
$$

304
303
275
45
299
51
2
88
441
4,800
332

310

309

276

36

238

59

2

90

448

5, 600

232

large amounts of fuel, highly insulated tanks should be considered. For airports with a fully developed infrastructure, optimum tanks would require a much lighter insulation. The infrastructure plays a significant role in hydrogen development, not only because hydrogen needs to be produced onsite from renewable resources and would require safe storage and filling systems to be certified, but also due to the reutilisation system required for hydrogen left at the aircraft when stopped or parked overnight.

Due to the uncertainty regarding the pace at which such infrastructure will be developed, the tanks considered in this paper are aluminium double-walled foam-insulated tanks with boil-off rates below $0.15 \%$ per hour. The weight of the tanks considered here is 1.22 times the weight of the hydrogen contained. This results in a gravimetric efficiency (ratio of weight of hydrogen to weight of hydrogen plus tank) of around 0.45 . Under optimum infrastructure development, the gravimetric efficiency could be increased to the $0.7+$ range.

The authors, based on established aircraft and engine design and performance correlations ${ }^{(13,19,20,21)}$, developed a method for the evaluation of aircraft and engine performance (Huete et al. 2020-1). Many iterations of different combinations were carried out. The final results of this analytical process are presented in Table 2, where the HVLMR, HVLLR and HVLER concepts are compared with the 'design donor' aircraft. These are used with the Cranfield propulsion system integration method Hermes/Orion ${ }^{(22)}$ to confirm the combined aircraft and engine performance. Hermes/Orion uses TURBOMATCH for engine performance calculations.

Figure 5a shows the airframe of the aircraft used for the study. The aircraft has two decks to carry passengers, the lower deck being larger than the upper one. The authors examined three variants of a hydrogen-fuelled airliner derived from this concept: HVLMR, HVLLR and HVLER; for hydrogen medium, hydrogen long and hydrogen extended range. The concepts of long and extended ranges apply to hydrogen in this case and imply much shorter flights than the capabilities of a modern conventional airliner. The first variant, HVLMR, considers the use of the upper deck to house fuel tanks, while the HVLLR is conceived with the fuel tank in the lower deck and HVLER with a combination. 

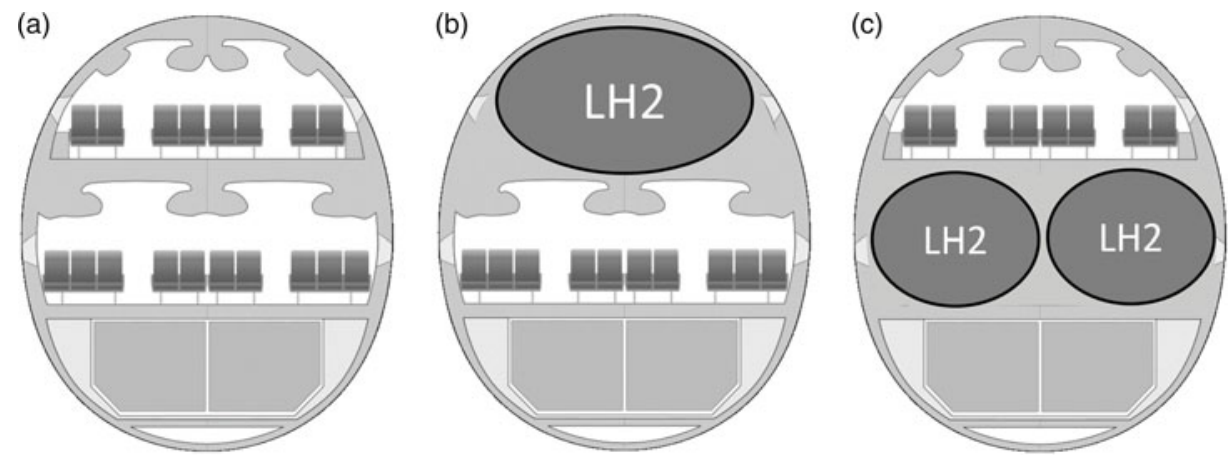

Figure 5 (a) Baseline image (b) HVLMR layout (c) HVLLR layout (Image from Ssolbergj, Steff and Clem Tillier - Creative Commons licensed modified by the authors).
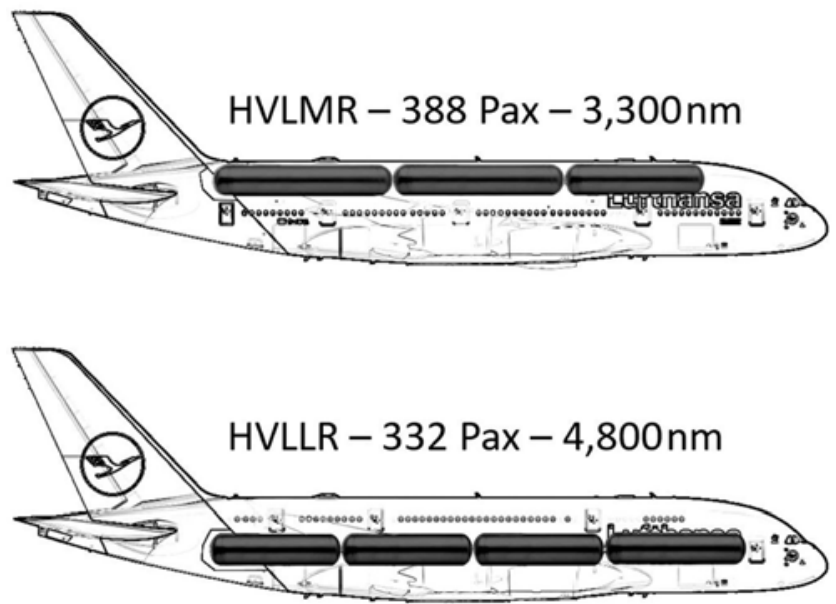

\section{$\mathrm{LH}_{2}$ Fuel Tank}

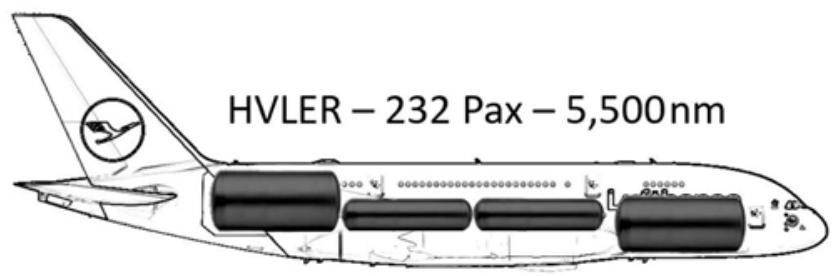

Figure 6. HVLMR, HVLLR and HVLER concepts. Images courtesy of Lufthansa ${ }^{(10)}$ and modified by the authors.

\subsection{INTEGRATED CAPABILITY}

To offer a visual illustration of the aircraft concepts, the authors modified existing aircraft $\operatorname{artwork}^{(10)}$ and produced authors impressions of the HVLMR, HVLLR and HVLER. These are shown in Fig. 6 with estimates of range and passenger capacity. Table 3 lists a compilation of distances between major cities obtained from Wikipedia to give a measure of the usefulness of the HVLMR, HVLLR and HVLER aircraft. 


\section{Table 3}

\section{Distances between selected airports, a measure of the usefulness of HVLMR, HVLLR and HVLER (Wikipedia)}

$\begin{array}{lcc}\text { Table of distances } & \mathbf{n m} & \mathbf{k m} \\ \text { London-Athens } & 1,293 & 2,395 \\ \text { Dublin-Moscow } & 1,514 & 2,804 \\ \text { Singapore-Shanghai } & 2,048 & 3,792 \\ \text { New York-San Francisco } & 2,235 & 4,139 \\ \text { Boston-Los Angeles } & 2,241 & 4,150 \\ \text { Seattle-Honolulu } & 2,329 & 4,313 \\ \text { New York-London } & 3,016 & 5,586 \\ \text { Singapore-Sydney } & 3,404 & 6,305 \\ \text { Miami-Rio de Janeiro } & 3,618 & 6,700 \\ \text { Mumbai-Singapore } & 3,697 & 6,846 \\ \text { Madrid-Miami } & 3,836 & 7,105 \\ \text { Johannesburg-Rio de Janeiro } & 3,850 & 7,130 \\ \text { London-Mumbai } & 3,890 & 7,204 \\ \text { Lagos-Mumbai } & 4,116 & 7,622 \\ \text { Shanghai-Sydney } & 4,262 & 7,893 \\ \text { Madrid-Johannesburg } & 4,362 & 8,078 \\ \text { Sydney-Honolulu } & 4,401 & 8,150 \\ \text { Dublin-San Francisco } & 4,417 & 8,180 \\ \text { Tokyo-San Francisco } & 4,476 & 8,290 \\ \text { London-Shanghai } & 4,968 & 9,201\end{array}$

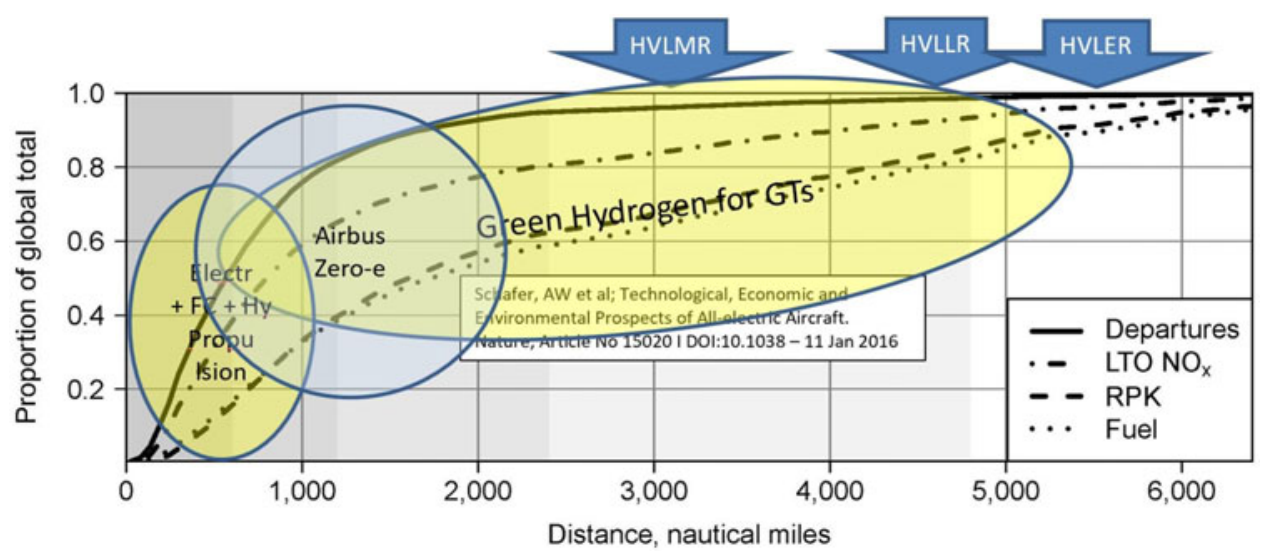

Figure 7. HVLMR, HVLLR and HVLER capabilities ${ }^{(8)}$ annotated by the authors and including the authors understanding of the Airbus Zero-e concepts ${ }^{(23)}$.

The estimated vehicle capability, for an introduction-accelerator philosophy, is good. It does not match the payload or very long ranges of current aircraft using conventional fuels, but it fares very well as an introductory accelerator technology to decarbonise aviation. Furthermore, Fig. 7 shows that the range offered covers more than $98 \%$ of existing aircraft 
departures and accounts for $90 \%$ of total fuel consumption. So, the remaining small fraction of very long-range flights could be serviced with one additional stop. It is expected that, in this scenario, the impact on fuel consumption will actually be beneficial because it is well known that significantly less fuel is required if a conventional aircraft flies two $8,000 \mathrm{~km}$ legs instead of a $16,000 \mathrm{~km}$ flight nonstop, although in the case of hydrogen the benefit will be significantly smaller because of the much higher energy density of the fuel, requiring a smaller fuel fraction of the total aircraft weight.

During this early investigation, it became apparent that the tank gravimetric efficiency is a parameter that will very significantly influence the performance characteristics of the integrated aircraft and powerplant. A detailed evaluation is being pursued independently (Huete et al. 2020-2)

\subsection{CONCLUSIONS AND RECOMMENDATIONS}

This paper describes an investigation into three hypothetical propulsion integration configurations with different tank locations for storing fuel. The investigation is philosophical in nature and is backed by detailed calculations. A family of civil aircraft using hydrogen fuel in gas turbine engines could be developed using the main components of two existing aircraft as a basis for the design. A very large two-deck transport design would provide the fuselage, while the wings, engines and tail surfaces would be derived from a very long-range twin. The family would comprise three configurations: HVLMR, HVLLR and HVLER. This family exhibits a payload and range that is significantly smaller than the 'donor' aircraft, but its characteristics are sufficiently attractive to be considered as a launch option for a first generation of zerocarbon aircraft. The range of the HVLER is chosen strategically to allow flights from any point on the planet to any other with just one stop. Figure 7 shows the strategic positioning of the family.

There may be many candidate aircraft to enter early service, but HVLMR, HVLLR and HVLER appear to offer sufficient promise to be considered as first-generation candidates for larger vehicles with longer ranges. As technologies mature, the performance of the aircraft of later generations would be better. In this context, a parameter of crucial importance, the tank gravimetric efficiency, is currently being evaluated by authors examining the proposed concepts $^{(3)}$ and original analysis. Another aspect under investigation is the ability to burn hydrogen in the combustor with very low NOx emissions ${ }^{(1)}$. The approach in this investigation is to use combustors with very small orifices to mix air with fuel, procure good mixing characteristics delivering a lower primary zone fuel-to-air ratio and lower flame temperature, capitalising on the much wider flammability limits of hydrogen. This approach appears to be a good candidate solution at the expense of a small, acceptable weight and length penalty to the engine. Beyond carbon and NOx emissions, contrails also deserve detailed consideration. It is anticipated that, initially, contrail mitigation will be via rerouting flights ${ }^{(7)}$. This approach is very promising to completely avoid persistent contrails at the expense of a few (1-3) additional percent in fuel burn. The integration of the fuel system and the components required is likely to follow known approaches ${ }^{(24)}$ updated. Given the reduced luminosity of hydrogen flames, it is anticipated that heat transfer will be less aggressive than what is experienced with conventional fuels, so conventional combustor cooling arrangements are probably adequate. The same is argued here for turbine cooling requirements. Nonetheless, these matters deserve detailed examination. 
Current detailed work is showing ${ }^{(1)}$ that health and safety at airports and on aircraft can be managed by careful attention to detail and appropriate investments. There will be many certification hurdles, in particular arising from the need for extensive changes to certification rules. The development process could comprise two parallel streams. The first would focus on the development of the aircraft and engines using conventional fuel to test the handling quality of the vehicles. In parallel, an existing four-engine transport could be modified to use hydrogen fuel in two of the four engines to test all the systems associated with hydrogen in a twinjet; the remaining two engines would operate on conventional fuel while the hydrogen systems are developed to achieve high reliability and functionality. These parallel streams would probably last about a decade and serve as a platform for the dialogue with certification authorities to adapt rules to hydrogen fuel, supporting a zero-carbon reality.

Of course, there are also the questions of airport infrastructure and the production of zerocarbon hydrogen on a vast scale. This may be from seawater electrolysis to prevent unhelpful competition with scarce freshwater resources. Undoubtedly, all of these developments will cost hundreds of billions of pounds (or euros or US dollars), but the authors firmly believe that these costs are acceptable to migrate to zero carbon an industry that brings so many technical, social and economic benefits.

\section{ACKNOWLEDGEMENTS}

The authors acknowledge the support of Lufthansa via the provision of artwork used in this paper and for their interest in this environment-enhancing project.

\section{REFERENCES}

1. Enable H2. Website - https://www.enableh2.eu/ accessed $11^{\text {th }}$ April 2020.

2. Cryoplane Project, EU Press Release. Meeting the challenges in aircraft emissions: Commission looks into clean alternatives to fossil fuel, 2002, https://ec.europa.eu/commission/ presscorner/detail/en/IP_02_769.

3. Verstraete, D. The Potential Of Liquid Hydrogen For Long Range Aircraft Propulsion, Doctoral Thesis, Cranfield University, 2009.

4. Giffard, H. Making Jet Engines in World War II: Britain, Germany, and the United States, University of Chicago Press, Chicago and London. ISBN 022638859X, 9780226388595, 2016.

5. Kaufman, H.R. High Altitude Performance Investigation of J65-B-3 Turbojet Engine with Both JP-4 and Gaseous Hydrogen Fuels. NACA RM E57A11, 1957.

6. Tupolev Public Stock Company. Cryogenic Aircraft, https://web.archive.org/web/20130218231 656/http://www.tupolev.ru/English/Show.asp?SectionID=82, Accessed 12 April 2020.

7. Nalianda, D. Impact of environmental taxation policies on civil aviation - a techno-economic environmental risk assessment, Doctoral Thesis, Cranfield University, 2012.

8. Schafer, A.W., Barrett, S.R.H., Doyme, K., Dray, L.M., Gnadt, A.R., Self, R., O’Sullivan, A., SYNodinos, A.P. and ToRIJA, A.J. Technological, economic and environmental prospects of allelectric aircraft. Nature, 2016, Article No 15020, (I), 1038.

9. Nalianda, D. and Singh, R. Turbo-electric distributed propulsion-benefits, challenges and opportunities, (AEAT-03-2014-0035), J Aircr Eng Aerosp Technol, 2014, 86, (6), pp 543-549. https://doi.org/10.1108/AEAT-03-2014-0035.

10. Lufthansa. https://www.lufthansa.com/us/en/388, accessed 20 April 2020.

11. Jane's Aero Engines. Editor - Mark Daly, IHS Markit, 2018.

12. Rolls-Royce. https://www.rolls-royce.com/products-and-services/civil-aerospace/airlines/trentxwb.aspx\#/ accessed 1 June 2020.

13. Nikolaidis, T. TURBOMATCH- Gas Turbine Performance Simulation - User Manual, unpublished, Cranfield University, 2017. 
14. Palmer, J.R. and Pilidis, P. Gas Turbine Theory and Performance, Thermal Power MSc course notes, unpublished, Cranfield University, 2013.

15. Cohen, H., Rogers, G.F.C. and Saravanamuttoo, H.I.H. Gas Turbine Theory, 7th ed. Pearson. Harlow. Page 68. ISBN 9781-292-09309-3, 2017.

16. GoldBerg, C. Techno-economic, Environment and Risk Analysis of an Aircraft Concept with Turbo-electric Distributed Propulsion, Doctoral Thesis, Cranfield University, 2018.

17. Goldberg, C., Nalianda, D., Singh, R. and Pilidis, P. Turbo-electric Distributed Propulsion (TeDP) Vehicle Study, including Techno-economic, environment and risk analysis (TERA) Final Research Grant (NNX13AI78G) Report to NASA, Cranfield University (Confidential), 2017.

18. Goldberg, C., Nalianda, D., MacManus, D., Pilidis, P. and Felder, J. Method for simulating the performance of a boundary layer ingesting propulsion system at design and off-design, Aerosp Sci Technol, 2018, 78, 312-319.

19. FIELDING, J.P. Introduction to Aircraft Design, 2nd ed. Cambridge University Press, Cambridge. ISBN - 978-1-107-68079-1, 2017.

20. RAYMER, D.P. Aircraft Design - A Conceptual Approach, AIAA - ISBN 0-930403-51-7, 1992.

21. Torenbeek, E. Synthesis of Subsonic Airplane Design, ISBN 90-247-27724-3, 1982.

22. Nalianda, D., Goldberg, C. and Mastropierro, F. Hermes / Orion Aircraft Performance and Propulsion System Integration Model, unpublished, Cranfield University Manual, 2020.

23. RAeS, Royal Aeronautical Society, Airbus Pivots to Hydrogen, Aerospace, November 2020.

24. Brewer, G.D., Morris, R.E., Davis, G.W., Versaw, E.F., Cunnington Jr, G.R., Riple, J.C., Baerst, C.F. and GARMONG, G. Study of LH2 fueled subsonic passenger transport aircraft. Final Report Volume II. NASA CR- 145369, 1978, 2. 